\title{
Prevelance of Pregnancy Complications among Women Aged 15 - 49 in Oğuzeli, Turkey
}

\author{
Neriman Aydin'1, Birgul Ozcirpici ${ }^{*}$, Mithat Temizer ${ }^{2}$ \\ ${ }^{1}$ Department of Public Health, Faculty of Medicine, Gaziantep University, Gaziantep, Turkey \\ ${ }^{2}$ Şahinbey Community Health Center, Gaziantep, Turkey \\ Email: naydin@gantep.edu.tr, *ozcirpici@gantep.edu.tr, mithattemizer@hotmail.com
}

How to cite this paper: Aydin, N., Ozcirpici, B. and Temizer, M. (2016) Prevelance of Pregnancy Complications among Women Aged 15 - 49 in Oğuzeli, Turkey. Open Journal of Obstetrics and Gynecology, 6, 623629.

http://dx.doi.org/10.4236/ojog.2016.611078

Received: July 28, 2016

Accepted: September 19, 2016

Published: September 22, 2016

Copyright $\odot 2016$ by authors and Scientific Research Publishing Inc. This work is licensed under the Creative Commons Attribution International License (CC BY 4.0).

http://creativecommons.org/licenses/by/4.0/

\section{Abstract}

As maternal deaths have decreased worldwide, increasing attention has been placed on the study of severe obstetric complications, such as hemorrhage, eclampsia, and obstructed labor, to identify where improvements can be made in maternal health. The objective of this study was to determine pregnancy complications and prenatal care among women aged 15 - 49 in Oğuzeli, Turkey, and to provide data for prevention in the field. This descriptive, cross-sectional study was conducted between February and May 2013 in Oguzeli distinct, Turkey. The total women registered to family doctors in Oğuzeli was listed and, 470 women were selected using a stratified and simple random sampling technique. Pregnancy complications were asked for the last pregnancy of each women. Of the women, 23.9\% $(n=109)$ declared that they experienced pregnancy complications during their pregnancies. The most frequent problems were anemia (11.1\%) hypertension $(3.7 \%)$ and diabetes mellitus $(2.4 \%)$ respectively. Women having chronic diseases before their pregnancy were more likely to have pregnancy complications compared to healthy women $(p=0.005)$. The mean number of prenatal care among women having pregnancy complications was $5.47 \pm$ 3.57 , while it was $3.84 \pm 3.00$ among healthy women $(\mathrm{p}=0.000)$. Women having chronic diseases should be handled carefully and, pregnancy should be delayed until the chronic disease's remission. Family planning in primary care is the key measure to archive this. Early diagnosis of hypertension among young women is highly important for the women's and infants's health during pregnancy, and for the women's future heath. During prenatal care, women should be trained about correct eating habits and activity.

\section{Keywords}

Pregnancy Complications, Women Aged 15 - 49, Prenatal Care 


\section{Introduction}

Complications of pregnancy are health problems that occur during pregnancy. They can involve the mother's health, the infant's health, or both. Some women have health problems that arise during pregnancy, and other women have health problems before they become pregnant that could lead to complications [1]. Getting early and regular prenatal care can help decrease the risk for problems by enabling health care providers to diagnose, treat, or manage conditions before they become serious. Some common complications of pregnancy include, but are not limited to: high blood pressure, gestational diabetes, preeclampsia, preterm labor, pregnancy loss [2].

While most pregnancies and births are uneventful, all pregnancies are at risk. Around $15 \%$ of all pregnant women develop a potentially life-threatening complication that calls for skilled care and some will require a major obstetrical intervention to survive. Midwives and doctors: support activities for the improvement of all district health services; strive for efficient and reliable referral systems; monitor the quality of health care services; advocate for community participation in health related matters [3].

Developing countries contributed highest level of maternal mortality due to obstetric complications. Women awareness of obstetric danger sign to recognize complications to seek medical care early is the first intervention in an effort to decrease maternal death [4]. It is very important for women to receive health care before and during pregnancy to decrease the risk of pregnancy complications [1].

As maternal deaths have decreased worldwide, increasing attention has been placed on the study of severe obstetric complications, such as hemorrhage, eclampsia, and obstructed labor, to identify where improvements can be made in maternal health [5]. The objective of this study was to determine pregnancy complications and prenatal care among women aged 15 - 49 in Oğuzeli, Turkey, and to provide data for prevention in the field.

\section{Metarial and Methods}

This descriptive, cross-sectional study was conducted between February and May 2013 in Oğuzeli distinct, Turkey. Oğuzeli is a rural region with a population of 29.620 in 2013, not too far from the city center of Gaziantep.

The population of the study was women aged $15-49$, married at least once, living in Oğuzeli $(\mathrm{N}=3615)$. The least sample size representing women aged 15 - 49 in Oğuzeli region was determined as 347 by the formula $\mathrm{N}=\mathrm{Nt}^{2} \mathrm{pq} / \mathrm{d}^{2}(\mathrm{P}=0.5, \mathrm{~d}=0.05, \alpha=0.05)$ [6]. The total women registered to family doctors in Oğuzeli was listed and, 470 women was selected using a stratified and then simple random sampling technique. The inclusion criteria were to be married and then having pregnancy. The exclusion criteria were to be a woman having no pregnancy.

The questionnaire, prepared from an intensive literature review, had 51 items including sociodemographic and obstetric questions. The questions included; first marital and pregnancy ages, number of pregnancies, abortions and stillbirths, questions about pregnancy complications for the last pregnancy, prenatal care and place of birth. A pi- 
lot study was conducted to test the applicability of the questionnaire to women out of sample. After modifications, it was conducted by face to face technique by a public health assistant in participant's residency. Pregnancy complications were asked for the last pregnancy of each woman.

All participants orally gave informed consent for the study, the study protocol was approved by the Gaziantep University Clinical Research Ethics Committee (date: 22.01. 2013 number $=-37$ ).

Limitations of this study was recall bias and, of the data, not being obtained by follow-up of women.

The data was evaluated on a computer using SPSS 22.0. In the statistical analyses, chi-square and descriptive analysis were conducted. The level of significance is $\mathrm{p}<0.05$.

\section{Results}

Of the participiants $(n=470), 63 \%(n=296)$ had primary education, $73.6 \%(n=346)$ had social security and, $37.3 \%$ had consanguineous marriage $(n=175)$. Majority of women were housewives $(95.3 \%)(n=448)$ (Table 1$)$. The mean age of first marriage

Table 1. Distribution of the study participiants according to some sociodemographic characteristics.

\begin{tabular}{|c|c|c|}
\hline Sociodemographic characteristics & $\mathbf{n}$ & $\%$ \\
\hline \multicolumn{3}{|l|}{ Educational level of women } \\
\hline Illiterate & 61 & 13.0 \\
\hline Literate & 28 & 6.0 \\
\hline Primary & 296 & 63.0 \\
\hline Secondary & 43 & 9.1 \\
\hline High School & 34 & 7.2 \\
\hline University & 8 & 1.7 \\
\hline \multicolumn{3}{|l|}{ Educational level of husbands } \\
\hline Illiterate & 7 & 1.5 \\
\hline Literate & 7 & 1.5 \\
\hline Primary & 224 & 47.7 \\
\hline Secondary & 119 & 25.3 \\
\hline High School & 81 & 17.2 \\
\hline University & 32 & 6.8 \\
\hline \multicolumn{3}{|l|}{ Current employment status of women } \\
\hline Working & 22 & 4.7 \\
\hline Housewife & 448 & 95.3 \\
\hline \multicolumn{3}{|l|}{ Social security } \\
\hline Yes & 346 & 73.6 \\
\hline No & 124 & 26.4 \\
\hline \multicolumn{3}{|l|}{ Consanguineous marriage } \\
\hline No & 295 & 62.7 \\
\hline First degree & 106 & 22.6 \\
\hline Second degree and far more & 69 & 14.7 \\
\hline Total & 470 & 100.0 \\
\hline
\end{tabular}


and first pregnancy were $19.5 \pm 3.8(\min =13, \max =39), 21.5 \pm 4.3(\min =13, \max =$ 38) respectively. The mean number of pregnancies was $3.9 \pm 2.2(\mathrm{Max}=11)$. Of the women, $48.7 \%$ had pregnancies 4 and more $(n=470)$. Women having primary education and lower (75.3\%) were more likely to have pregnancies 4 and more compared to educated higher than primary school $(42.8 \%)(p<0.05)$. Similarly, housewives were more likely to have pregnancies 4 and more than working women (50.2\% versus $22.7 \%$ ) $(\mathrm{p}<0.05)$.

\section{Results for the Last Pregnancy}

A total of 457 women answered the questions for the last pregnancy because 13 women had never had pregnancy. 38.1\% did not get iron supplements during their last pregnancy. Of the women, $14.04 \%(n=64)$ had at least one chronic disease before they got pregnant. Women having 4 and more pregnancies were less likely to have prenatal care $(\mathrm{p}<0.05)$. Of the women, 23.9\% $(\mathrm{n}=109)$ declared that they experienced pregnancy complications during their pregnancies. Distribution of pregnancy complications are shown in Table 2. The most frequent problems were anemia, hypertension and diabetes mellitus respectively. Women having chronic diseases before their pregnancy were more likely to have pregnancy complications compared to healthy women ( $\mathrm{p}=$ $0.005)$. The mean age of healthy women $(37.39 \pm 8.24)$ and women having pregnancy complications $(37.11 \pm 8.24)$ was not statistically significant $(\mathrm{p}=0.746)$. The mean number of prenatal care among women having pregnancy complications was $5.47 \pm$ 3.57 , while it was $3.84 \pm 3.00$ among healthy women $(\mathrm{p}=0.000)$.

Table 2. Distribution of pregnancy complications.

\begin{tabular}{ccc}
\hline Pregnancy Complications & n & \% * \\
\hline Hyperemesis gravidarum & 6 & 1.3 \\
Anemia & 51 & 0.8 \\
Placenta Previa & 4 & 3.7 \\
Hypertension & 17 & 2.4 \\
Diabetes Mellitus & 11 & 0.6 \\
Blood clotting disorder & 3 & 1.3 \\
Infection & 6 & 2.1 \\
Abortion threat & 10 & 0.2 \\
Facial Paralysis & 1 & 0.2 \\
Anxiety & 1 & 0.2 \\
Myoma uteri & 1 & 0.2 \\
Nephrolithiasis & 1 & 2 \\
\hline
\end{tabular}

${ }^{*}$ A total of 457 women answered this question $(n=457), 13$ women had never had pregnancy. 


\section{Discussıon}

Annually, approximately 9.5 million women around the world suffer from pregnancyrelated complications, and over 300,000 die [5]. Pregnancy, the antepartum period, delivery and the postpartum period are very important for maternal and child morbidity and mortality. Appropriate health care during these periods is critical for reducing the risks of various problems and improving the quality of life for women and children [7].

According to results of the study, $14.04 \%$ had at least one chronic disease before they got pregnant and, women having chronic diseases before their pregnancy were more likely to have pregnancy complications compared to healthy women $(\mathrm{p}=0.005)$. This shows the importance of 15 - 49 age follow-ups in the primary care. These women should be handled carefully and, pregnancy should be delayed until the chronic disease's remission. Family planning in primary care is the key measure to archive this. A study revealed that better self-rated health in pregnancy predicted fewer childbirth complications; lower odds of cesarean delivery; and fewer maternal health problems at 6 months, 18 months, and 3 years after delivery [8].

Pregnancy-induced hypertension induces maternal and fetal damage, but it can also be the beginning of future metabolic and vascular disorders. The relative risk of chronic hypertension after pregnancy-induced hypertension is between 2.3 and 11, and the likelihood of subsequent development of type 2 diabetes is multiplied by 1.8. The postpartum period is a great opportunity to intervene on lifestyle, obesity, make an early diagnosis of chronic hypertension and DM and provide the necessary treatments to prevent cardiovascular complications in women [9]. Hypertension (3.7\%) is the second most frequent problem declared by the participants. Early diagnosis of hypertension among young women is highly important for the women's and infants' health during pregnancy, and for the women's future heath. In the primary care, monitoring blood pressure for every person, married or not, will help to prevent complications.

Of the participants, $38.1 \%$ declared that they did not get iron supplements during their last pregnancy. Whereas, the most frequent problem in the last pregnancy declared by women was anemia (11.1\%). Results of a study has shown that iron deficiency anemia was frequent among young women, low socioeconomic group, multifarious and, these women were prone to high complications such as ante partum hemorrhage, renal failure, disseminated intravascular coagulation and maternal mortality [10]. Early detection and treatment of anemia, among young women and pregnant, is highly important and the easiest pregnancy problem that can be solved.

Evidence indicates that advanced maternal age is associated with adverse obstetric and perinatal outcomes [11]. Contrarily to this knowledge, our results showed that the mean age of healthy women $(37.39 \pm 8.24)$ and women having pregnancy complications $(37.11 \pm 8.24)$ was not statistically significant $(\mathrm{p}=0.746)$. We think this may be associated with probable inactivity, incorrect eating habits among young women.

Pregnancy outcomes were in general worse in gestational diabetes mellitus women. Treatment with insulin was associated with a significantly lower risk of complications [12]. Third most frequent pregnancy complication was diabetes mellitus (2.4\%). During 
prenatal care, women should be trained early signs of diabetes, correct eating habits and activity.

It is very important for women to receive health care before and during pregnancy to decrease the risk of pregnancy complications [1]. According to the study results; women having 4 and more pregnancies were less likely to have prenatal care $(\mathrm{p}<0.05)$. This is an important finding because risk of complications may rise by age and by the number of pregnancy. Primary care workers and obstetricians should be careful about monitoring women having high pregnancies. The mean number of prenatal care among women having pregnancy complications was $5.47 \pm 3.57$, while it was $3.84 \pm 3.00$ among healthy women $(\mathrm{p}=0.000)$. This is a positive finding about monitoring pregnancies with complications, showing the awareness of health worker, pregnant women or both.

According to the results of a study by Amenu and et al. 55.1\% participants were knowledgeable about danger signs of obstetric complications and, maternal and husband educational level, family monthly income $\geq 1500$, being multipara, antenatal care follow-up during last pregnancy were variables found to be significantly associated with women's knowledge on danger signs of obstetric complications [4]. Women awareness of obstetric danger sign to recognize complications to seek medical care early is the first intervention in an effort to decrease maternal death. Women attributed their lifethreatening experiences to societal and socioeconomic factors that led to delays in seeking timely medical care by decision makers, usually husbands or other male relatives [5]. Therefore, training husbands and other relatives of women, especially in women having low educational and social status, is highly important to manage pregnancy complications and maternal death.

\section{Conclusions}

A higher number of average pregnancies in our study, affected by women's education and employment status; affecting prenatal care and pregnancy outcomes, is an issue that needs to be focused strongly. Women having chronic diseases should be handled carefully and, pregnancy should be delayed until the chronic disease's remission. This shows the importance of 15 - 49 age follow-ups in the primary care. Although, it is known that advanced maternal age is associated with adverse obstetric and perinatal outcomes, our results showed that the mean age of healthy women and women having pregnancy complications were similar. This may be associated with probable inactivity, incorrect eating habits among young women. Training young girls about correct nutritional habits and raising their activity will help their better future pregnancy outcomes.

As "The Safe Motherhood" program emphasizes [13], providing access to appropriate maternity care; ensuring the availability of a trained birth attendant; providing a clean environment for the birth; ensuring ease of referral to specialist care; screening women for complications remaining watchful for indicators of complications in all women; providing readily available emergency obstetric care; educating and informing women about their pregnancy and birth and about warning signs of emergencies, so that they know what to expect and can participate in their own care; providing easy 
access to family planning services; setting protocols for dealing with major problems such as hemorrhage or eclampsia are highly important for handling with complications especially in developing countries. Prenatal care visits as a unique opportunity to provide a safe pregnancy and delivery and, also increases the likelihood of a skilled attendant being present at the birth.

\section{References}

[1] Pregnancy Complications. http://www.cdc.gov/reproductivehealth/maternalinfanthealth/pregcomplications.htm

[2] What Are Some Common Complications of Pregnancy? https://www.nichd.nih.gov/health/topics/pregnancy/conditioninfo/pages/complications.aspx

[3] (2007) Managing Complications in Pregnancy and Childbirth: A Guide for Midwives and Doctors. World Health Organization.

[4] Amenu, G., Mulaw, Z., Seyoum, T. and Bayu, H. (2016) Knowledge about Danger Signs of Obstetric Complications and Associated Factors among Postnatal Mothers of Mechekel District Health Centers, East Gojjam Zone, Northwest Ethiopia, 2014. Scientifica, Article ID: 3495416. http://dx.doi.org/10.1155/2016/3495416

[5] Shegufta, S.S., Alain, B.L.,Barkat, U., Hasmot, A., Mahbubur, R., Sucheta, M., Nusrat, J., Abu, A.S., Keith, P.W. and Parul, C. (2011) Accounts of Severe Acute Obstetric Complications in Rural Bangladesh. BMC Pregnancy and Childbirth, 11, 76. http://dx.doi.org/10.1186/1471-2393-11-76

[6] Sümbüloğlu, V. and Sümbüloğlu, K. (2005) Sampling Methods and Sample Size in Clinical and Community Research. Alp Ofset, Ankara, 103. (İn Turkish)

[7] World Health Organization (2012) Far More Pregnant Women Getting Prenatal Care. http://www.who.int/mediacentre/news/releases/2004/pr22/en/index.html

[8] Stepanikova, I., Kukla, L. and Svancara, J. (2016) Predictive Value of Self-Rated Health in Pregnancy for Childbirth Complications, Adverse Birth Outcomes, and Maternal Health. International Journal of Gynecology \& Obstetrics. http://dx.doi.org/10.1016/j.ijgo.2016.03.029

[9] Alvarez-Alvarez, B., Martell-Claros, N., Abad-Cardiel, M. and García-Donaire, J.A. (2016) Hypertensive Disorders during Pregnancy: Cardiovascular Long-Term Outcomes. Hipertensión y Riesgo Vascular. (İn Spanish)

[10] Khaskheli, M.N., Baloch, S., Sheeba, A., Baloch, S. and Khaskheli, F.K. (2016) Iron Deficiency Anaemia İs Still a Major Killer of Pregnant Women. Pakistan Journal of Medical Sciences, 32, 630-634. http://dx.doi.org/10.12669/pjms.323.9557

[11] Zapata-Masias, Y., Marqueta, B., Gómez Roig, M.D. and Gonzalez-Bosquet, E. (2016) Obstetric and Perinatal Outcomes in Women $\geq 40$ Years of Age: Associations with Fetal Growth Disorders. Early Human Development, 100, 17-20.

http://dx.doi.org/10.1016/j.earlhumdev.2016.04.010

[12] Mahalakshmi, M.M., Bhavadharini, B., Maheswari, K., Kalaiyarasi, G., Anjana, R.M., Ranjit, U., Mohan,V., Joseph, K., Rekha, K., Nallaperumal, S., Malanda, B., Kayal, A., Belton, A. and Uma, R. (2016) Comparison of Maternal and Fetal Outcomes among Asian Indian Pregnant Women with or without Gestational Diabetes Mellitus: A Situational Analysis Study (WINGS-3). Indian Journal of Endocrinology and Metabolism, 20, 491-496. http://dx.doi.org/10.4103/2230-8210.183469

[13] Essential Antenatal, Perinatal and Postpartum Care. 12. http://www.euro.who.int/_data/assets/pdf_file/0013/131521/E79235.pdf 
Submit or recommend next manuscript to SCIRP and we will provide best service for you:

Accepting pre-submission inquiries through Email, Facebook, LinkedIn, Twitter, etc. A wide selection of journals (inclusive of 9 subjects, more than 200 journals)

Providing 24-hour high-quality service

User-friendly online submission system

Fair and swift peer-review system

Efficient typesetting and proofreading procedure

Display of the result of downloads and visits, as well as the number of cited articles

Maximum dissemination of your research work

Submit your manuscript at: http://papersubmission.scirp.org/

Or contact ojog@scirp.org 